\title{
Композиционные сорбирующие изделия на основе силикагеля для осушки газовых сред
}

\author{
Соловей В.Н., Самонин В.В., Спиридонова Е.А., Подвязников М.Л. \\ Санкт-Петербургский государственный технологический институт, Санкт-Петербург
}

Поступила в редакцию 6.07.2018 г.

DOI: https://doi.org/10.17308/sorpchrom.2019.19/741

В работе рассматриваются сорбционные изделия, предназначенные для удаления влаги из газовых сред, на основе силикагеля марки КСМГ и полимерных матриц - водных растворов полиакриламида и поливинилового спирта. Определены физико-химические и прочностные характеристики разработанных материалов в различных условиях их эксплуатации. На протяжении 40 циклов осушки влажного воздуха $\left(90 \%\right.$ отн. при $\left.(24 \pm 1)^{\circ} \mathrm{C}\right)$ до остаточного влагосодержания 0.3 г/м ${ }^{3}$ исследовались сорбционные свойства полученных изделий. Установлено, что применение поливинилового спирта в качестве матрицы позволяет продлить срок службы блочного изделия в сравнении с насыпной шихтой силикагеля при сохранении прочностных характеристик материала.

Ключевые слова: адсорбция, осушка газовых сред, композиционные сорбирующие изделия, силикагель, полимерные матрицы.

\section{Composite sorbent products based on silica gel for drying gas environments}

\author{
Solovei V.N., Samonin V.V., Spiridonova E.A., Podvyaznikov M.L. \\ St. Petersburg State Technological Institute (Technical University, St. Petersburg
}

Sorption products intended for removal of moisture from gaseous environments, based on silica gel KSMG and polymeric matrices - aqueous solutions of polyacrylamide and polyvinyl alcohol are considered in this work. In the dynamic conditions of operation of the flow adsorber, the sorption properties of the obtained products in cyclic sorption processes were studied at elevated values of the relative humidity of the dried air (90\%) and thermal desorption during 40 operating cycles. It is shown that the use of polyvinyl alcohol as a matrix provides higher sorption characteristics of the material and allows them to be retained for a longer time in the multi-cycle operation of the block product in comparison with the batch of silica gel. As a result of the conducted researches the strength characteristics of the developed materials in different conditions of their work are determined. The block product retained its integrity in the following tests: aging at low $\left(-76^{\circ} \mathrm{C}\right)$ and high temperatures $\left(180^{\circ} \mathrm{C}\right)$, cyclic operation in sorption mode - thermoregeneration (40 cycles), vibration loading $(10 \mathrm{~Hz})$ and pressure drop $(\triangle \mathrm{P}=0.4 \mathrm{MPa})$, which is a high performance indicator of the developed KSAM. The results of a comprehensive study of the sorption, strength and mechanical properties of a block product based on silica gel with polyvinyl alcohol make it possible to conclude that the obtained high-strength and heat-resistant block products are promising in various wet air drying systems.

Keywords: adsorption, drying of gas environments, composite sorbent products, silica gel, polymer matrix

\section{Введение}

Осушка газов, выполняющих функцию технологических сред, сорбционным методом широко используется в химической, газовой, нефтеперерабатывающей, 
пищевой промышленности для улучшения качества сырья и продуктов, создания необходимой реакционной среды, для осушки фреонов холодильных машин, а также для сохранения в работоспособном состоянии электронно-оптических приборов и др. Поддержание влажности воздуха на заданном уровне является одной из основных задач обеспечения длительной работы систем жизнеобеспечения, включающих в себя комплекс технических средств, обеспечивающих необходимые условия жизнедеятельности человека в замкнутом объеме на космических кораблях и подводных лодках. Для поглощения и удаления влаги используются высокопористые материалы - сорбенты различной природы (силикагель, цеолит, активный оксид алюминия и др.), как с нанесенными специальными гигроскопичными добавками, так и без них [1-6]. Но при использовании таких сорбентов возникает ряд проблем: отсутствие равномерности распределения в сложных конструкциях, вызывающее пристеночный эффект, а также невысокая износостойкость и, как следствие, пыление, приводящее к уносу частиц адсорбента с газовыми потоками. Для улучшения сорбционных и прочностных показателей имеющихся сорбентов в настоящее время используют гибридные материалы, полученные за счет взаимодействия компонентов с различной химической природой, формирующих определенную структуру, отличающуюся от структур исходных реагентов, но часто наследующую определенные свойства и функции исходных структур [1, 7-9].

Таким образом, для совершенствования процесса сорбционной осушки воздуха разработка новых гибридных материалов, обладающих высокими сорбционными и прочностными показателями, является актуальной задачей в научном и практическом плане. К таким материалам можно отнести композиционные сорбционноактивные материалы (КСАМ), выполненные в виде блоков различной конфигурации, состоящих из матрицы, выполняющей роль связующего компонента материала, определяющей прочность адсорбента как единого целого при воздействии механических, аэродинамических и других нагрузок, в качестве которой в большинстве случаев используют полимерные вещества, и наполнителя - материала, обладающего высокой сорбционной активностью.

Важной задачей технологии КСАМ является получение материалов, в первую очередь, с высокой сорбционной активностью. В связи с этим необходимо в процессе получения блочного сорбирующего изделия сохранять поглотительные свойства наполнителя путем применения определенного типа матриц. Наибольший интерес среди матриц различных классов представляет полимерная система, применение которой в качестве связующего дает возможность направленно формировать структуру и свойства КСАМ [7]. В соответствии с вышеизложенным целью проводимой работы является разработка блочного изделия на основе сорбирующего материала и полимерной матрицы, предназначенного для осушки газовых сред, обладающих, как высокими сорбционными, так и прочностными свойствами.

\section{Эксперимент}

В работе получение высокопрочного блочного сорбирующего изделия осуществлялось в виде закрепленной в обечайке адсорбера шихты отечественного промышленного крупного силикагеля мелкопористого гранулированного (КСМГ, ГОСТ 3956-76) и органического полимерного связующего. В роли связующего использовались нетоксичные и наиболее эффективные по функциональному назначению, термостойкие, водорастворимые полимеры - полиакриламид (ПАА, ТУ 6-01-1049-92) и поливиниловый спирт (ПВС, ГОСТ 10779-78).

Соловей и др. / Сорбционные и хроматографические процессы. 2019. Т. 19. № 2 
Акриловый карбоксилсодержащий полимер - полиакриламид является хорошим пленкообразующим веществом. Исходная пленка ПАА обладает довольно значительной прочностью на разрыв [10]. ПАА хорошо растворим в воде, имеет достаточно высокую термостойкость $\left(180^{\circ} \mathrm{C}\right)$, в температурном интервале $(180-200)^{\circ} \mathrm{C}$ начинает разлагаться.

Поливиниловый спирт - водорастворимый, термопластичный полимер. Водные растворы ПВС обладают хорошими клеящими свойствами, образуя прозрачные, прочные к истиранию пленки. ПВС характеризуется широким молекулярномассовым распределением, наличием в макромолекулах разветвлений, ацетатных и вицинальных гидроксильных групп. Также поливиниловый спирт и пленки на его основе характеризуются определенной степенью сорбционной емкости [11-13]. Температура стеклования ПВС $85-90^{\circ} \mathrm{C}$, кратковременное термическое воздействие при температуре свыше $150^{\circ} \mathrm{C}$ вызывает сшивание цепей ПВС с потерей молекул воды. Разлагается ПВС при $230^{\circ} \mathrm{C}$.

Методика получения блочных изделий заключалась в проливе связующего (водного раствора полимера) через насыпную шихту силикагеля при постоянном продуве воздуха для удаления избытка раствора с дальнейшей температурной обработкой при $180^{\circ} \mathrm{C}$ в течение 2 часов. При получении материалов таким методом растворитель (дистиллированная вода) испаряется при повышении температуры, а на поверхности гранул силикагеля образуется монолитная полимерная пленка сетчатой структуры, фиксирующая положение гранул силикагеля относительно друг друга. Сетчатая структура пленки обеспечивает свободный доступ молекул адсорбата к активной поверхности материала. Концентрация полимера в водном растворе при использовании ПАА составляла 0.5 и $1 \%$ (мас.), при использовании ПВС - $1 \%$ (мас.).

Применимость полученных сорбирующих блочных изделий на основе полимерных матриц в качестве осушителей проверяли путем проведения процесса осушки влажного воздуха в динамических условиях. Условия эксперимента: диаметр адсорбера - 2.5 см, высота блочного изделия, закрепленного в обечайке адсорбера 22 см, температура воздуха $-24 \pm 1{ }^{\circ} \mathrm{C}$, относительная влажность воздуха - $90 \pm 1 \%$, объемный расход воздуха -2.5 дм $^{3} /$ мин. Процесс осушки воздуха осуществляли до появления за слоем сорбента проскоковой концентрации - абсолютной влажности воздуха 0,3 г/м ${ }^{3}$, контролируемой по показаниям термогигрометра ИВА-6Б. Схема установки для проведения процессов сорбции паров воды представлена на рис. 1.

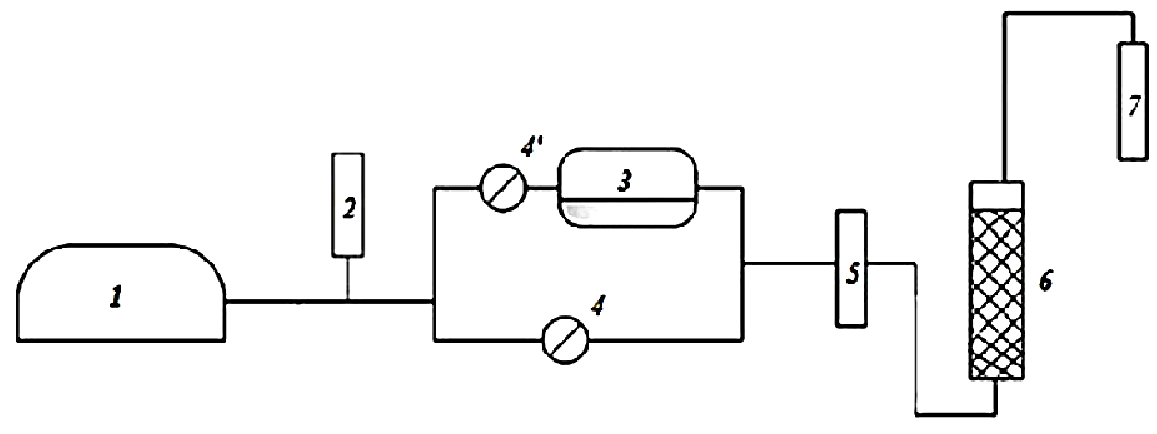

Рис. 1. Схема установки для проведения процессов сорбции паров воды 1 - компрессор; 2 - ротаметр; 3 - барботажная испарительная емкость с водой;

4, 4' - запирающие устройства; 5, 7 - термогигрометры; 6 - адсорбер с исследуемым материалом

Воздух с помощью компрессора (1) подавался на заполненную водой барботажную испарительную емкость (3) для создания необходимой влажности воздуха, которая регулировалась запирающими устройствами (4) и (4'). Влажность и температура воздуха замерялась термогигрометром (5), а расход - ротаметром (2). Далее 
воздух с заданной влажностью подавался на адсорбер с исследуемым материалом (6). На выходе из адсорбера влажность воздуха замерялась термогигрометром (7). При достижении влагосодержания, соответствующего проскоковой концентрации, процесс останавливался. Регенерацию отработанных материалов проводили в сушильном шкафу непосредственно в адсорбере с постоянным продувом воздуха при температуре $180^{\circ} \mathrm{C}$ в течение 2 часов. Режим регенерации обусловлен физикохимическими свойствами сорбента для создания блочного изделия - силикагеля и температурными характеристиками полимерных связующих.

Эффективный коэффициент диффузии, как количественная характеристика скорости переноса влаги по пористой структуре сорбента, определяли по формуле, приведенной в [4]:

$$
D=\frac{K \times r^{2}}{\pi^{2} \times \tau_{0,5}}
$$

где $\mathrm{r}$ - радиус гранулы; К - коэффициент, зависящий от формы гранулы (для сферической гранулы силикагеля $\mathrm{K}=0.308) ; \tau_{0,5}$ - время полуотработки адсорбционной емкости; изучалась при использовании единичной гранулы силикагеля в статических условиях. Для поддержания постоянной концентрации паров воды $\left(94 \% \mathrm{RH}, 21 \pm 1^{\circ} \mathrm{C}\right)$ использовали эксикатор с заданной влажностью. Непрерывным взвешиванием гранулы силикагеля на торзионных весах определяли величину привеса до тех пор, пока образец не достигнет насыщения парами воды.

\section{Обсуждение результатов}

На рис. 2 представлены выходные кривые влагопоглощения на насыпной шихте и на блочных изделиях на основе ПАА в 1-м и 20-м циклах осушки воздуха до наступления проскока влаги за слоем осушителя 0.3 г/м ${ }^{3}\left(\mathrm{C} / \mathrm{C}_{0}=0.16\right)$.

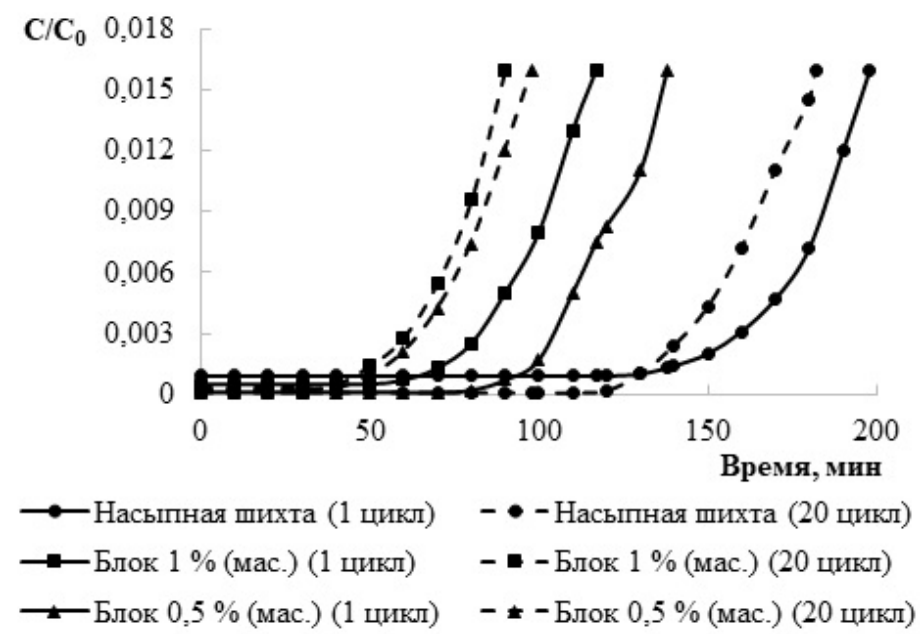

Рис. 2. Выходные кривые влагопоглощения насыпной шихтой и блочными изделиями на основе ПАА

Из полученных данных видно, что степень осушки воздуха для всех образцов достаточно высокая. Максимальная температура точки росы, как характеристика глубины осушки воздуха, для всех образцов на протяжении 20 циклов работы находилась в интервале от -70 до $-60^{\circ} \mathrm{C}$. Выходные кривые влагопоглощения на всех исследуемых образцах симметричны, что говорит об отсутствии влияния введения связующего на характер протекания процессов сорбции воды. При этом заметно, что 
блочные изделия на основе ПАА матрицы относительно насыпной шихты силикагеля имеют сравнительно невысокое время защитного действия (ВЗД), что непосредственно связано с сорбционной емкостью материала. На протяжении 20 циклов работы насыпная шихта силикагеля не теряет своих сорбционных характеристики, поддерживая при этом стабильную глубину осушки, что нельзя сказать о блочных материалах с ПАА матрицей. Обобщенные результаты многоцикловых исследований работы насыпной шихты и блочного изделия на основе ПАА матрицы представлены в таблице 1.

Таблица 1. Результаты исследований по осушке влажного воздуха на блочных изделиях с ПАА матрицей и насыпной шихте в циклических процессах сорбции - десорбции

\begin{tabular}{|c|c|c|c|c|c|}
\hline Образец & Цикл & $\begin{array}{c}\text { Абсолютная } \\
\text { влажность } \\
\text { воздуха, г/м }{ }^{3}\end{array}$ & $\begin{array}{c}\text { Время защит- } \\
\text { ного действия, } \\
\text { мин }\end{array}$ & $\begin{array}{c}\text { Эффективный } \\
\text { коэффициент } \\
\text { диффузии, м²/с }\end{array}$ & $\begin{array}{l}\text { Динамическая } \\
\text { емкость, мг/г }\end{array}$ \\
\hline \multirow{2}{*}{$\begin{array}{l}\text { Насыпная } \\
\text { шихта }\end{array}$} & 1 & 17.3 & 198 & $11.7 \cdot 10^{-11}$ & 106 \\
\hline & 20 & 17.5 & 182 & $11.0 \cdot 10^{-11}$ & 99 \\
\hline \multirow{2}{*}{$\begin{array}{c}\text { Блок } \\
1 \% \text { (мас.) } \\
\text { ПАА }\end{array}$} & 1 & 18.9 & 117 & $9.4 \cdot 10^{-11}$ & 68 \\
\hline & 20 & 18.7 & 90 & $7.5 \cdot 10^{-11}$ & 52 \\
\hline \multirow{2}{*}{$\begin{array}{c}\text { Блок } \\
0.5 \% \text { (мас.) } \\
\text { ПАА } \\
\end{array}$} & 1 & 17.6 & 138 & $10.1 \cdot 10^{-11}$ & 75 \\
\hline & 20 & 18.4 & 98 & $7.7 \cdot 10^{-11}$ & 55 \\
\hline
\end{tabular}

Использование в качестве связующего ПАА, наносимого на силикагель из водного раствора 1\% (мас.) ПАА, оказывает значительное влияние на сорбционные характеристики наполнителя - силикагеля КСМГ. На 1 цикле сорбции влаги динамическая емкость блочного изделия составила 68 мг/г, что на 36\% ниже динамической емкости насыпной шихты, время защитного действия блочного изделия с $1 \%$ (мас.) ПАА на $41 \%$ меньше в сравнении с насыпной шихтой. На 20 цикле осушки влажного воздуха сорбционные характеристики блочного изделия на основе $1 \%$ (мас.) ПАА значительно ухудшились. Динамическая емкость изделия по прошествии 20 циклов снизилась на 23\%, что соответственно привело к более быстрому проскоку влаги. При этом динамическая емкость насыпной шихты силикагеля по прошествии 20 циклов снизилась всего на 6\%.

Снижение концентрации ПАА с $1 \%$ (мас.) до $0.5 \%$ (мас.) не привело к улучшению сорбционных характеристик блочного изделия. На 1 цикле осушки воздуха не была достигнута динамическая емкость как для насыпной шихты. На 20 цикле осушки воздуха ВЗД составило 98 мин, а динамическая емкость - 55 мг/г, что на $46 \%$ и на $44 \%$ соответственно меньше относительно насыпной шихты (В3Д 182 мин, динамическая емкость - 99 мг/г).

Таким образом, в ходе проведенных исследований выявлено, что использование ПАА в качестве связующего для получения блочных изделий, подвергающихся в дальнейшем многократной термической регенерации, нецелесообразно. Плотная пленка полимера оказывает влияние на массоперенос адсорбата, замедляя диффузию влаги к активной поверхности силикагеля. А под воздействием внешних факторов (влаги, тепла, кислорода воздуха) в циклических процессах сорбции - десорбции деструктирующаяся пленка ПАА способствует ухудшению сорбционных характеристик наполнителя силикагеля КСМГ, что приводит к снижению работоспособности блочного материала. Во время многократной термообработки в области повышенных температур $\left(180^{\circ} \mathrm{C}\right)$ полимерное связующее претерпевает термическую деструк- 
цию, что приводит к старению и разложению ПАА. Процесс деструкции ПАА выражается физико-химическими превращениями полимера [14]: выходом летучих продуктов посредством молекулярной реакции по функциональным группам с последующей деструкцией макроцепей, при этом происходит постепенное изменение окраски полимера (от желтой до темно-коричневой).

Применение ПВС в качестве связующего способствует улучшению сорбционных характеристик блочного изделия. На рисунке 3 представлены выходные кривые влагопоглощения насыпной шихты и блочными изделиями на основе ПВС в 1 , 20, 30 и 40 циклы осушки воздуха до наступления проскока влаги за слоем осушителя в количестве 0.3 г/м $\mathrm{M}^{3}\left(\mathrm{C} / \mathrm{C}_{0}=0.16\right)$.

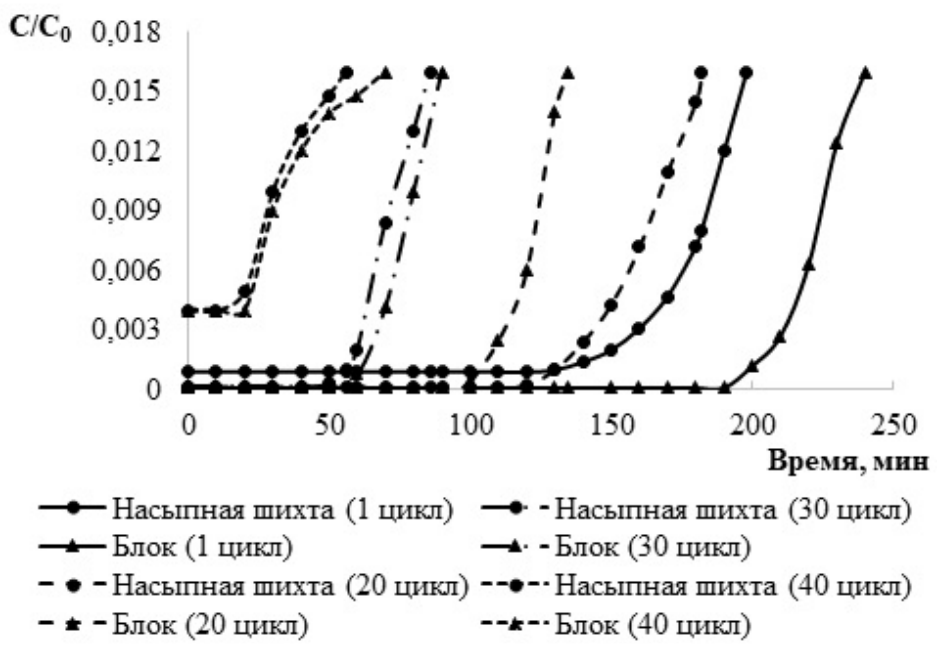

Рис. 3. Выходные кривые влагопоглощения насыпной шихтой и блочным изделием на основе ПВС

Полученные экспериментальные результаты свидетельствуют, что блочные материалы с ПВС матрицей по степени осушки не уступают исходному силикагелю. Наблюдается более высокая длительность работы сорбирующего изделия в сопоставлении с насыпной шихтой до наступления проскока. Повышение продолжительности осушки воздуха с достижением более высокой глубины осушки с использованием блочного изделия, вероятно, обусловлено хорошей газопроницаемостью пленки ПВС, которая, в свою очередь, обеспечивая активный транспорт влаги по пористой структуре блочного материала, способствует более равномерному распределению влаги по всему блочному изделию и высокой степени насыщения каждой гранулы силикагеля. Подобный эффект отмечался и в более ранних работах $[15,16]$. Однако, с увеличением количества циклов регенерации сорбирующего материала продолжительность работы и глубина осушки воздуха, как блочным изделием на основе ПВС матрицы, так и насыпной шихтой силикагеля снижаются. Обобщенные результаты многоцикловых исследований представлены в таблице 2.

После проведения первого цикла сорбции динамическая емкость блока составила 138 мг/г, время защитного действия - 240 мин, в то время как у насыпной шихты эти показатели значительно ниже (время защитного действия - 198 мин, динамическая емкость - 106 мг/г). Анализ совокупности результатов по исследованию сорбционных характеристик полученного блочного изделия позволяет утверждать, что проницаемость и гидрофильность пленки полимерной матрицы обеспечивает повышение емкостных характеристик блочного изделия по сравнению с исходной насыпной шихтой силикагеля, что положительно отражается при работе в динамических условиях. Многократная термическая регенерация не приводит к выравнива- 
нию сорбционных показателей относительно насыпной шихты. К 40 циклу динамическая емкость блочного изделия выше на $18 \%$, чем у насыпной шихты, что обеспечивает большее время защитного действия. Увеличение времени защитного действия полученного блочного изделия объясняется улучшением кинетических параметров процесса адсорбции, чему способствует, как структура полимерной матрицы, так и более совершенная, по сравнению с насыпной шихтой, структура самого КСАМ.

Таблица 2. Результаты исследований по осушке влажного воздуха на блочных изделиях с ПВС матрицей и насыпной шихте в циклических процессах сорбции - десорбции

\begin{tabular}{|c|c|c|c|c|c|}
\hline Образец & Цикл & $\begin{array}{l}\text { Абсолютная } \\
\text { влажность } \\
\text { воздуха, г/м }\end{array}$ & $\begin{array}{c}\text { Время защит- } \\
\text { ного действия, } \\
\text { мин }\end{array}$ & $\begin{array}{c}\text { Эффективный } \\
\text { коэффициент } \\
\text { диффузии, м²/с }\end{array}$ & $\begin{array}{l}\text { Динамическая } \\
\text { емкость, мг/г }\end{array}$ \\
\hline \multirow{4}{*}{$\begin{array}{c}\text { Насыпная } \\
\text { шихта }\end{array}$} & 1 & 17.3 & 198 & $11.7 \cdot 10^{-11}$ & 106 \\
\hline & 20 & 17.5 & 182 & $11.0 \cdot 10^{-11}$ & 99 \\
\hline & 30 & 19.7 & 86 & $7.2 \cdot 10^{-11}$ & 53 \\
\hline & 40 & 20.1 & 56 & $5.3 \cdot 10^{-11}$ & 35 \\
\hline \multirow{4}{*}{$\begin{array}{c}\text { Блок } \\
1 \% \text { (мас.) } \\
\text { ПВС }\end{array}$} & 1 & 18.7 & 240 & $17.3 \cdot 10^{-11}$ & 138 \\
\hline & 20 & 20.8 & 135 & $12.1 \cdot 10^{-11}$ & 86 \\
\hline & 30 & 20.8 & 90 & $8.3 \cdot 10^{-11}$ & 58 \\
\hline & 40 & 20.0 & 70 & $6.9 \cdot 10^{-11}$ & 43 \\
\hline
\end{tabular}

Стоит еще раз упомянуть о гидрофильных свойствах пленки ПВС, которая вносит существенный вклад в сорбционную составляющую блочного изделия, обеспечивая как активный транспорт влаги по пористой структуре блочного материала, так и возможность образования водородных связей между молекулами сорбата (воды) и активных центров полимерной сетки. Особенно значительно это проявляется при повышенной влажности воздуха. Наглядный пример иллюстрируется на рис. 4, где представлены кинетические кривые влагопоглощения насыпной шихты и блочного изделия с ПВС матрицей при относительном давлении паров воды $\mathrm{P} / \mathrm{P}_{\mathrm{S}}=0.94$ и $\mathrm{t}=23^{\circ} \mathrm{C}$ в начальный промежуток времени контакта сорбента с влажным воздухом в статических условиях.

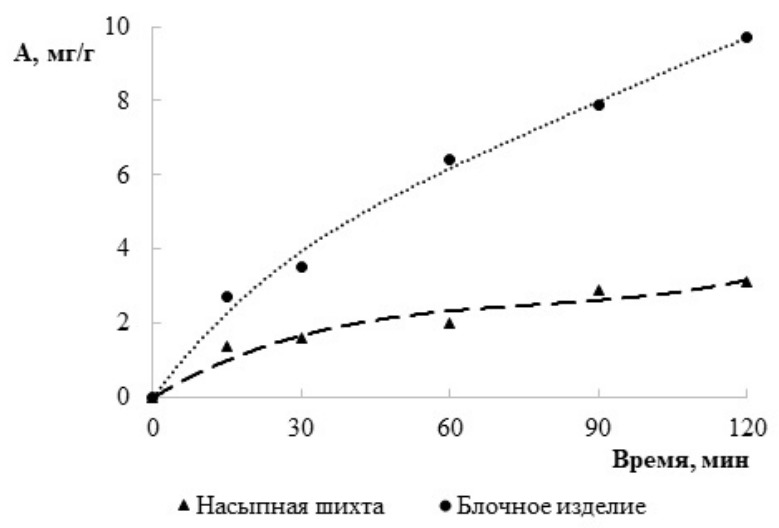

Рис. 4. Зависимость адсорбционной емкости насыпной шихты силикагеля и блочного изделия ПВС матрицей от времени контакта сорбента с влажным воздухом

Но следует отметить, что к 40 циклу время защитного действия, как насыпной шихты, так и блочного изделия, уменьшается вследствие того, что в процессе эксплуатации снижается адсорбционная емкость самого силикагеля. На рисунке 5 представлено изменение динамической адсорбционной емкости насыпной шихты сили-

Соловей и др. / Сорбционные и хроматографические процессы. 2019. Т. 19. № 2 
кагеля и блочного изделия на основе ПВС матрицы в зависимости от количества циклов сорбции - десорбции.

Аналогичные сведения встречаются в литературе, так в [17] указано, что при эксплуатации установки осушки газов, по истечении (2.0-2.5) лет многоцикловой работы остаточная адсорбционная емкость силикагеля по парам воды составляет всего (5-11) \% (мас.).

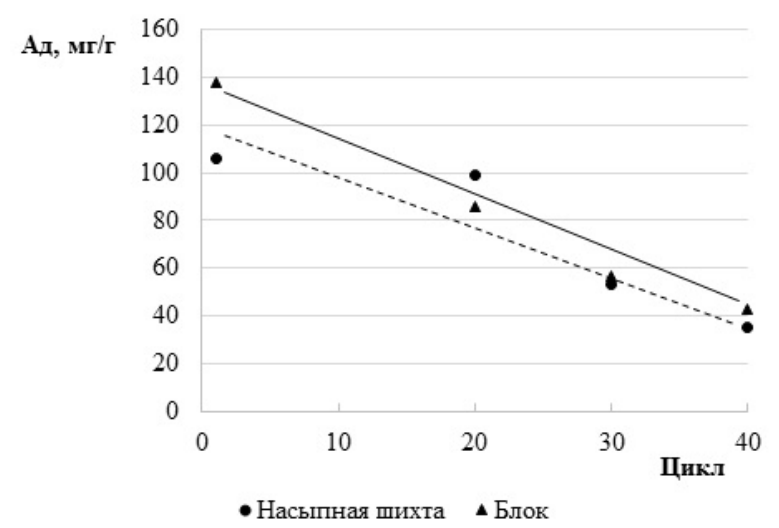

Рис. 5. Изменение динамической емкости насыпной шихты и блочного изделия на основе ПВС с увеличением количества циклов сорбции - десорбции

Изменение сорбционных характеристик силикагеля может быть вызвано следующими причинами. Во-первых, это может быть связано со старением силикагеля. Причина старения силикагеля состоит в укрупнении глобул адсорбента и отщепление от них ОН-групп, которые являются центрами адсорбции воды [2]. Старение происходит тем интенсивнее, чем чаще проводится высокотемпературная регенерация. Сначала начинается процесс укрупнения пор, затем постепенное дегидроксилирование поверхности с уменьшением поверхностной концентрации свободных силанольных групп. Дегидроксилирование поверхности силикагеля может снижать специфичность молекулярной адсорбции, уменьшая возможность образования водородной связи $[18,19]$. Во-вторых, постепенная дезактивация силикагеля может происходить по причине его закоксовывания. Поскольку при получении гранулированного силикагеля в промышленной практике гидрогель формируется в виде сферических частиц только при пропускании его через слой масла, впоследствии масло, оставшиеся во вторичной пористости адсорбента и на поверхности гранул, в процессе десорбции закоксовывается. Данный процесс сопровождается процессом сгорания, в результате чего происходит снижение активности адсорбента. В-третьих, промышленный силикагель содержит небольшое количество примесей - оксиды различных металлов (алюминия, железа, кальция и др.). Некоторые из них являются катализаторами и способствуют протеканию крекинга масла при регенерации. В результате чего на поверхности силикагеля также образуется кокс, снижающий адсорбционную активность силикагеля.

Полученные в результате выполнения данной работы сведения позволяют утверждать, что введение матрицы ПВС для скрепления гранул силикагеля в единое блочное сорбирующее изделие приводит к некоторого рода стабилизации сорбционных свойств силикагеля и предотвращает резкое падение адсорбционной емкости силикагеля и, как следствие, времени защитного действия.

Особо значимой характеристикой блочного сорбента является его прочность. Высокая прочность материала гарантирует отсутствие пыления и образования трещин при воздействии механических и гидравлических нагрузок. В ходе эксплуата- 
ции систем осушки воздуха с насыпной шихтой силикагеля вследствие движения воздуха происходит истирание гранул с образованием пыли, при этом средний эквивалентный диаметр гранул силикагеля может снижаться с (3 - 4) мм до 1 мм [17]. Образовавшаяся пыль частично уносится, а частично остается в адсорбере, блокируя свободное пространство между гранулами, тем самым приводя к потерям механической энергии на преодоление аэродинамического сопротивления. В связи с вышесказанным проведен ряд испытаний на определение устойчивости блочного изделия к различного рода нагрузкам: цикловой, термической, вибрационной, пневматической (таблица 3).

Таблица 3. Результаты испытаний блочного изделия на устойчивость к различного рода нагрузкам

\begin{tabular}{|c|c|c|}
\hline Вид нагрузки & Условия нагрузки & Результат \\
\hline Цикловая нагрузка & 40 циклов сорбции - десорбции & Без разрушений \\
\hline \multirow{2}{*}{ Термическая нагрузка } & 40 циклов регенерации & Без разрушений \\
\cline { 2 - 3 } & Хранение $780^{\circ} \mathrm{C}, 2$ чут при $-76^{\circ} \mathrm{C}$ & Без разрушений \\
\hline Вибрационная нагрузка & 10 ч работы при частоте 10 Гц & Без разрушений \\
\hline Пневматическая нагрузка & Перепад давления 0.4 МПа & Без разрушений \\
\hline
\end{tabular}

После многократного (40 циклов) термического воздействия $\left(180^{\circ} \mathrm{C}, 2\right.$ ч) визуальными и тактильными методами была проведена оценка прочности испытуемого блока, в ходе которой изменение прочности образца не обнаружено. Однако, после воздействия высоких температур, к 40 циклу наблюдается некоторое потемнение блочного изделия, что может быть обусловлено частичной термоокислительной деструкцией ПВС, которая также может приводить к старению материала при продолжительной эксплуатации. Также при удалении сорбированной воды и дегидроксилировании поверхности силикагеля, являющимся наполнителем блочного материала, может меняться химическая активность всего КСАМ, вследствие гидролиза полимерной матрицы под действием воды [20].

При определении морозостойкости материала, блочные изделия помещали на 7 суток в контейнер с сухим льдом, который создавал температуру $-76^{\circ} \mathrm{C}$. В результате - изменение прочности образцов обнаружено не было.

Для создания режима пневматической нагрузки в металлическом адсорбере с закрепленным блочным изделием создавалось давление 0.5 МПа, затем давление резко сбрасывалось до атмосферного и вновь нагнеталось до 0.5 МПа. Опыт повторялся 5 раз, в результате которого изменение прочности КСАМ не было обнаружено.

Проверка на виброустойчивость осуществлялась при частоте колебаний блочного изделия, закрепленного в адсорбере, 10 Гц в течение 10 ч. В результате изменение прочности не обнаружено. При проведении аналогичных исследований с насыпной шихтой силикагеля было замечено изменение фракционного состава: $2.7 \%$ гранул с диаметром > 3 мм растрескались с образованием более мелкой фракции.

Важным условием применения блочных изделий является их аэродинамическое сопротивление, при оптимальном значении которого обеспечивается надежная работа сорбционных установок. Установлено, что аэродинамическое сопротивление блочного сорбента сопоставимо с сопротивлением слоя насыпной шихты.

Результаты комплексного исследования сорбционных, прочностных и механических свойств блочного изделия с 1\% (мас.) ПВС матрицей позволяют сделать вывод о перспективности использования полученного высокопрочного и термостойкого блочного изделия в различных системах осушки влажного воздуха. 


\section{Заключение}

Получены высокопрочные блочные сорбирующие изделия на основе микропористого наполнителя - силикагеля марки КСМГ и полимерной матрицы - поливинилового спирта, предназначенные для поглощения паров воды в системах подготовки газовых сред, например, на подвижных объектах и станциях, функционирование которых связано со значительными вибрационными, механическими и другого рода нагрузками.

В динамических условиях работы проточного адсорбера исследованы сорбционные свойства полученных изделий в циклических процессах сорбции при повышенных значениях относительной влажности осушаемого воздуха (90\%) и термической десорбции в течение 40 циклов работы. Показано, что применение поливинилового спирта в качестве матрицы обеспечивает более высокие сорбционные характеристики материала, время защитного действия изделия в среднем в 1.2 раза больше, чем у насыпной шихты силикагеля; позволяет более длительное время сохранять их при многоцикловой работе блочного изделия по сравнению с насыпной шихтой силикагеля.

В результате проведенных комплексных исследований определены прочностные характеристики разработанных материалов в различных условиях их работы. Блочное изделие сохранило свою целостность при следующих испытаниях: выдержка при низких $\left(-76^{\circ} \mathrm{C}\right)$ и высоких температурах $\left(180^{\circ} \mathrm{C}\right)$, циклическая работа в режиме сорбция - терморегенерация (40 циклов), вибронагрузка (10 Гц) и перепад давления $(\Delta \mathrm{P}=0.4 \mathrm{MПа})$, что служит высокими показателями эксплуатационной надежности разработанного КСАМ.

\section{Список литературы}

1. Самонин В.В, Подвязников М.Л., Спиридонова Е.А. и др. Сорбционная осушка газовых и жидких сред. СПб. Наука. 2011. $138 \mathrm{c}$.

2. Шумяцкий Ю.И. Промышленные адсорбционные процессы. М. КолосС. 2009. $183 \mathrm{c}$.

3. Ломовцева Е.Е., Ульянова М.А., Андреев В.П. и др. // Вестник международной академии холода. 2011. № 4. С. 54-57.

4. Кельцев Н.В. Основы адсорбционной техники. М. Химия. 1984. 592 с.

5. Фотин Б.С. Очистка и осушка газов. СПб. Издательство СПбГТИ(ТУ). 1997. 80 с.

6. Аристов Ю.И., Гордеева Л.Г., Токарев М.М. Композитные сорбенты «соль в пористой матрице»: синтез, свойства, применение. Новосибирск: Издательство СО РАН. 2008. $362 \mathrm{c}$.

7. Самонин В.В., Подвязников М.Л., Никонова В.Ю. и др. Сорбирующие материалы, изделия, устройства и процессы управляемой адсорбции. СПб. Наука. 2009. 271 с.
8. Ломовцева Е.Е. Дис. канд. техн. наук. Тамбов, 2014. 220 с.

9. Феропонтова Л.Л. Дис. канд. техн. наук. M., 2016. 148 c.

10. Куренков В.Ф. // Соросовский образовательный журнал. 1997. № 5. С. 48-53.

11. Амерханова Ш.К., Шляпов Р.М., Уали А.С. // Сорбиионные и хроматографические проиессы. 2012. Т. 12. № 6. С. 875-883.

12. Кулагина Г.С., Чалых А.Е., Герасимов В.К. и др. // Высокомолекулярные соединения. Серия А. 2007. Т. 48. № 4. С. 654-662.

13. Кулагина Г.С. Дис. канд. хим. наук. М. 2007. $175 \mathrm{c}$.

14. Заиков Г.Е. // Успехи химии. 1991. Т. 60. № 10. C. 2220-2249.

15. Федоров Н.Ф., Ивахнюк Г.К, Самонин В.В. и др. // Журнал прикладной химии. 1990. Т. 64. № 5. C. 1054-1059.

16. Самонин В.В., Федоров Н.Ф. // Журнал прикладной химии. 1997. Т. 70. № 1. С. 51-54.

17. Технология переработки природного газа и конденсата: Справочник : в 2 ч. М.: ООО «Недра - Бизнесцентр». 2002.Ч.1.517 с. 
18. Киселев А.В. Межмолекулярные взаимодействия в адсорбции и хроматографии. М. Высшая школа. 1986. 360 с.
19. Химия привитых поверхностных соединений. Под ред. Г.В. Лисичкина. М. ФИЗМАТЛИТ, 2003. 592 с.

20. Брык М.Т. Деструкция наполненных полимеров. М. Химия. 1989. 192 с.

\section{References}

1. Samonin V.V, Podvyaznikov M.L., Spiridonova E.A. et al., Sorbcionnaya osushka gazovyx i zhidkix sred. SPb., Nauka, 2011, $138 \mathrm{p}$.

2. Shumyackij Yu.I., Promyshlennye adsorbcionnye process, M., KolosS, 2009, 183 p.

3. Lomovceva E.E., Ulyanova M.A., Andreev V.P. et al., Vestnik mezhdunarodnoj akademii kholoda, 2011, No 4, pp. 54-57.

4. Kelcev N.V., Osnovy adsorbcionnoj texniki, M., Khimiya, 1984, 592 p.

5. Fotin B.S., Ochistka i osushka gazov, SPb., Izdatelstvo SPbGTI(TU), 1997, 80 p.

6. Aristov Yu.I., Gordeeva L.G., Tokarev M.M., Kompozitnye sorbenty «sol v poristoj matrice»: sintez, svojstva, primenenie, Novosibirsk, Izdatelstvo SO RAN, 2008, $362 \mathrm{p}$.

7. Samonin V.V., Podvyaznikov M.L., Nikonova V.Yu. et al., Sorbiruyushhie materialy, izdeliya, ustrojstva i processy upravlyaemoj adsorbcii, SPb., Nauka, 2009, 271 p.

8. Lomovceva E.E., Dis. cand. tech. nauk. Tambov, 2014, $220 \mathrm{p}$.

9. Feropontova L.L., Dis. cand. tech. nauk. M., 2016.,148 p.

10. Kurenkov V.F., Sorosovskij obrazovatelnyj zhurnal, 1997, No 5, pp. 48-53.

Соловей Валерия Николаевна - к.т.н., старший преподаватель кафедры химии и технологии материалов и изделий сорбционной техники Санкт-Петербургского государственного технологического института (технического университета), Санкт-Петербург

Самонин Вячеслав Викторович - д.т.н, профессор, заведующий кафедрой химии и технологии материалов и изделий сорбционной техники Санкт-Петербургского государственного технологического института (технического университета), Санкт-Петербург
11. Amerxanova Sh.K., Shlyapov R.M., Uali A.S., Sorbtsionnye i khromatograficheskie protsessy, 2012, Vol. 12, No 6, pp. 875-883.

12. Kulagina G.S., Chalyx A.E., Gerasimov V.K. et al., Vysokomolekulyarnye soedineniya. Seriya A, 2007, Vol. 48, No 4, pp. 654-662.

13. Kulagina G.S. Dis. cand. chim. nauk. M., 2007. $175 \mathrm{p}$.

14. Zaikov G.E., Uspekhi khimii, 1991, Vol. 60, No 10, pp. 2220-2249.

15. Fedorov N.F., Ivaxnyuk G.K, Samonin V.V. et al., Zhurnal prikladnoj khimii, 1990, Vol. 64, No 5, pp. 1054-1059.

16. Samonin V.V., Fedorov N.F., Zhurnal prikladnoj khimii, 1997, Vol. 70, No 1, pp. 51-54.

17. Tekhnologiya pererabotki prirodnogo gaza i kondensata: Spravochnik : v 2 ch. M., OOO «Nedra - Biznescentr», 2002, Ch. 1, $517 \mathrm{p}$.

18. Kiselev A.V., Mezhmolekulyarnye vzaimodejstviya $\mathrm{v}$ adsorbcii i khromatografii, M., Vysshaya shkola, 1986, 360 p.

19. Khimiya privityx poverxnostnyx soedinenij, Pod red. G.V. Lisichkina, M., FIZMATLIT, 2003, 592 p.

20. Bryk M.T., Destrukciya napolnennyx polimerov, M., Khimiya, 1989, 192 p.

Solovei Valeria N. - candidate of technical Sciences, Senior Lecturer of the Department of Chemistry and Technology of Materials and Products of Sorption Technology of the St. Petersburg State Technological Institute (Technical University), St. Petersburg, e-mail: lera_solovei@mail.ru

Samonin Vyacheslav V. - doctor of technical Sciences, Professor, Head of the Department of Chemistry and Technology of Materials and Products of Sorption Technology of the St. Petersburg State Technological Institute (Technical University), St. Petersburg, e-mail: samonin@lti-gti.ru 
Спиридонова Елена Анатольевна - к.т.н., научный сотрудник кафедры химии и технологии материалов и изделий сорбционной техники Санкт-Петербургского государственного технологического института (технического университета), Санкт-Петербург

Подвязников Михаил Львович - д.т.н, профессор, профессор кафедры химии и технологии материалов и изделий сорбционной техники Санкт-Петербургского государственного технологического института (технического университета), Санкт-Петербург
Spiridonova Elena A. - candidate of technical Sciences, Scientific employee of the Department of Chemistry and Technology of Materials and Products of Sorption Technology of the St. Petersburg State Technological Institute (Technical University), St. Petersburg, e-mail: spiridonova_elena@live.ru

Podvyaznikov Mikhail L. - doctor of technical Sciences, Professor, Professor of the Department of Chemistry and Technology of Materials and Products of Sorption Technology of the St. Petersburg State Technological Institute (Technical University), St. Petersburg 